\title{
Nematode Infections Are Risk Factors for Staphylococcal Infection in Children
}

\author{
Sandra F Moreira-Silva, Alba LA Leite, Eliana F Brito, Fausto EL Pereira*/+
}

Unidade de Doenças Infecciosas, Hospital Infantil Nossa Senhora da Glória, Vitória, ES, Brasil *Núcleo de Doenças Infecciosas, CBM, UFES, Av. Marechal Campos 1468, 29040-091 Vitória, ES, Brasil

Nematode infection may be a risk factor for pyogenic liver abscess in children and we hypothesized that the immunomodulation induced by those parasites would be a risk factor for any staphylococcal infection in children. The present study was designed to compare, within the same hospital, the frequency of intestinal nematodes and Toxocara infection in children with and without staphylococcal infections. From October 1997 to February 1998, 80 children with staphylococcal infection and 110 children with other diseases were submitted to fecal examination, serology for Toxocara sp., evaluation of plasma immunoglobulin levels, and eosinophil counts. Mean age, gender distribution, birthplace, and socioeconomic conditions did not differ significantly between the two groups. Frequency of intestinal nematodes and positive serology for Toxocara, were remarkably higher in children with staphylococcal infections than in the non-staphylococcal group. There was a significant correlation between intestinal nematodes or Toxocara infection and staphylococcal infection in children, reinforced by higher eosinophil counts and higher IgE levels in these children than in the control group. One possible explanation for this association would be the enhancement of bacterial infection by the immunomodulation induced by helminth infections, due to strong activation of the Th2 subset of lymphocytes by antigens from larvae and adult worms.

Key words: nematodes - toxocariasis - helminthiasis - staphylococcus

In developed countries, immunodeficiency, foreign bodies, and impairment of inborn immune mechanisms are the main predisposing factors for staphylococcal infection (Feigin \& Cherry 1992). In developing countries, where staphylococcal infection in children appears to be more frequent in certain diseases, i.e. tropical pyomyositis (Gambhir et al. 1992) and pyogenic liver abscess (Hendricks et al. 1997), malnutrition is considered the main risk factor.

Lambertucci et al. (1990) and Teixeira et al. (1996) reported an association of acute toxemic schistosomiasis with pyogenic liver abscess. This finding was reproduced experimentally in mice infected with Schistosoma mansoni and inoculated by intravenous route with Staphylococcus aureus. These authors concluded that immunomodulation induced by the infection and trapping of bacteria in granulomas may explain the observed association.

In Vitória, State of Espírito Santo, Brazil, we reported that pyogenic liver abscess in children is frequently associated with peripheral eosinophilia, intestinal nematodes (Ferreira et al. 1996), and Toxocara infection (Pereira et al. 1999, Moreira-Silva \& Pereira 2000). These observations led us to hypothesize that such helminthic infections are risk factors for liver abscess by the same mechanisms proposed by Lambertucci et al. (1990), and Teixeira et al. (1996), for acute schistosomiasis. Also a relationship of

This research was supported by Facitec (Science and Technology Research Agency, Vitória, Espírito Santo, Brazil).

+Corresponding author. Fax: +55-27-3335.7206. E-mail: felp@ndi.ufes.br

Received 28 June 2001

Accepted 9 October 2001 pyomiositis and pyogenic liver abscess with Toxocara infection was reported in Belo Horizonte, State of Minas Gerais, Brazil (Rayes et al. 2000, 2001).

Since staphylococcal infections other than pyogenic liver abscess are frequent in children admitted to the "Nossa Senhora da Glória" Children's Hospital, we propose that nematode infection is a predisposing factor for all these infections. To test this hypothesis, we studied the occurrence of intestinal nematodes and Toxocara infection in children with staphylococcal infection as compared to children with other diseases admitted to the "Nossa Senhora da Glória" Children's Hospital.

\section{PATIENTS AND METHODS}

The "Nossa Senhora da Glória" Children's Hospital is a pediatric reference center belonging to the public health care system. In the last three years, the mean number of admissions has been 2,800 patients/year, and $60 \%$ of patients come from the outskirts of Greater Metropolitan Vitória (Vitória, Vila Velha, Cariacica, Serra, and Viana).

The study employed a case-control design, which included 80 children with various staphylococcal infections and 110 children with other diseases admitted to different wards in the Children's Hospital from October 1996 to February 1998. The only exclusion criterion was age under one year, due to the lower risk of helminth infection.

All the children were from lower-income families, and over $50 \%$ were from the urban periphery of Greater Metropolitan Vitória, where they were subjected to the same poor living conditions.

The staphylococcal infections diagnosed included pyoarthritis, pyomyositis, liver abscess, skin abscess, otitis, and pneumonitis with or without sepsis. The control group included neoplasms, tuberculosis, meningitis, viral infections, and streptococcal infections. The control 
group was randomized as follows: twice a week children admitted to various wards the day before, with diseases other than staphylococcal infection, were included as controls.

Diagnosis of staphylococcal infection was confirmed by blood or exudate culture. In the control group, all bacterial diseases were confirmed by blood or exudate culture to exclude staphylococcal infection.

Three methods were employed for the stool examination: Hoffmann-Pons-Janer, Baermann and Kato-Katz methods (Ash \& Oriel 1987).

Anti-Toxocara antibodies were investigated with an immunoenzymatic method (ELISA IgG), using a T. canis excretory-secretory antigen obtained from second-stage cultivated larvae (De Savigny et al. 1979). All sera were submitted to prior adsorption with Ascaris suum extract for $1 \mathrm{~h}$ at $37^{\circ} \mathrm{C}$. In accordance with standard values at the laboratory where the serology was performed, results were considered positive for titers over 500 .

Serum determination of $\operatorname{IgG}, \operatorname{IgM}$, and $\operatorname{IgA}$ was performed by turbidimetric assay using commercial kits (Turbiquant ${ }^{\circledR}$, Behring). Quantification of total serum IgE was obtained by microparticle enzyme immunoassay using commercial kits (IMx ${ }^{\circledR}$ Total IgE Assay, Abbott Laboratories).

Blood counts were performed by routine automatic methods. At least two blood counts were performed: one at admission and the other before discharge.

The research protocol was reviewed and approved by the Ethics Committee of the Biomedical Center, Federal University of Espírito Santo.

Statistical comparisons were calculated using EpiInfo version 6.1, and differences were considered significant for $\mathrm{p}$ values under 0.05 .

\section{RESULTS}

The diseases diagnosed in 80 children with staphylococcal infection are summarized in Table I. The diseases diagnosed in the control group are listed in Table II.

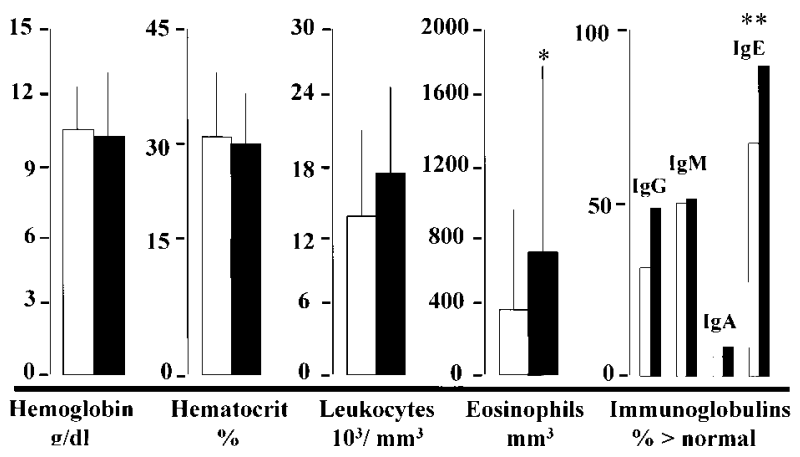

Hemoglobin, hematocrit, leukocytes and eosinophil counts, and plasma levels of immunoglobulins in children with staphylococcal infection ( $\mathrm{N}=80$; full bars) and controls with diseases other than staphylococcal infection ( $\mathrm{N}=110$; empty bars). Immunoglobulins (evaluated in 77 staphylococcal infection cases and in 53 controls) are indicated as the frequency of age adjusted values above the upper limit of normal range; $* \mathrm{p}=0,001$, Kruskal-Wallis test. $* * \mathrm{p}=0.027, \chi^{2}$ with Yates correction
Data on age sex, birthplace, frequency of intestinal helminths, and Toxocara serology are shown in Table III. There were significant differences between the two groups in the frequency of intestinal nematodes or positive serology for Toxocara, or both. There was no difference in age, gender distribution, or birthplace between the two groups.

Hematocrit, hemoglobin levels, total leukocytes and eosinophil counts, and serum immunoglobulin levels for the two groups are in the Figure. The blood eosinophil counts and the plasma IgE levels were significantly higher in patients with staphylococcal infection.

\section{DISCUSSION}

There was no significant difference between children with staphylococcal infections and the control group in relation to age, sex or birthplace (Table III). Although we did not investigate all the individual socioeconomic parameters (number of children in each family, mother's working conditions etc.) the two groups belong to the same socioeconomic conditions, since approximately $65 \%$ of children in each group came from the urban periphery, where the sanitary conditions are similar (Table I). Nutritional status of the two groups was also similar, as dem-

TABLE I

Staphylococcal infections diagnosed at admission in 80 children at "Nossa Senhora da Glória" Children's Hospital in Vitória, ES, Brazil

\begin{tabular}{lrr}
\hline Diagnosis at admisssion & $\mathrm{N}$ & $(\%)$ \\
\hline Osteomyelitis & 17 & $(21.2)$ \\
Pyoarthritis & 15 & $(18.7)$ \\
Osteomyelitis and pyoarthritis & 8 & $(10.0)$ \\
Cellulitis & 13 & $(16.2)$ \\
Pyomyositis & 8 & $(10.0)$ \\
Cellulitis and pyomyositis & 3 & $(3.7)$ \\
Liver abscess & 5 & $(6.2)$ \\
Pneumonitis & 4 & $(5.0)$ \\
Sepsis & 4 & $(5.0)$ \\
Epidural abscess & 2 & $(2.5)$ \\
Amygdalitis & 1 & $(1.2)$ \\
\hline Total & 80 & \\
\hline
\end{tabular}

TABLE II

Group of diseases diagnosed in 110 children admitted to the "Nossa Senhora da Gloria" Children's Hospital and used as controls for children with staphylococcal infection admitted to same hospital

\begin{tabular}{lr}
\hline Group of diseases & $\mathrm{N}$ \\
\hline Bacterial infections $^{a}$ & 44 \\
Viral infections $^{\text {Neoplasia }}$ & 17 \\
Malformations & 16 \\
Hematological diseases & 7 \\
Trauma & 6 \\
Other diseases & 4 \\
Total & 15 \\
\hline
\end{tabular}

$a$ : other than staphylococcal infections 
onstrated by similar values for hemoglobin and hematocrit. Although the two samples showed not significant differences in regard to several variables, we can not rule out several cofounders that are frequent when using inpatients samples. Thus all the conclusions may consider the caveats resulting the assumption that the two samples are comparable.

Frequency of intestinal nematodes and Toxocara infection was significantly higher in children with staphylococcal infection. The difference is even greater if we consider nematode infection or Toxocara infection in the two groups: $81.2 \%$ in children with staphylococcal infection and $41.6 \%$ in the control group (Table III) were infected by an intestinal nematode or showed positive serology for Toxocara.

The association of Toxocara infection with intestinal nematodes, especially Ascaris and Toxocara, was frequent, and higher in children with staphylococcal infection than in the control group ( $72.3 \%$ vs. $34.4 \%$, respectively). This association was not due to cross-reaction between Toxocara and Ascaris antigens, because all sera were adsorbed with $A$. suum antigen before testing. In addition, there were several cases of children with Ascaris infection in which the Toxocara serology was negative in both groups (17 and 12 cases, respectively, in the staphylococcal infection group and in controls). The frequent co-infection with the two nematodes can be explained by the same route of infection (ingestion of eggs) for Toxocara and Ascaris (Lynch et al. 1993).

The strong association between helminth infection (intestinal nematodes and/or Toxocara) and staphylococcal infections is reinforced by the higher frequency of peripheral eosinophilia (values above 600 eosinophils $/ \mathrm{mm}^{3}$ and higher IgE levels, in children with staphylococcal in- fection than in the control group). Eosinophilia was significantly higher in children with staphylococcal infection than in the control group at admission, when eosinopenia would be expected because of the stress induced by infection. In fact, the difference in eosinophilia between the two groups increased in the blood count before hospital discharge, when the children's health status was improved $\left(1418 \pm 3296\right.$ and $518 \pm 971$ eosinophils $/ \mathrm{mm}^{3}$ respectively, in staphylococcal infection cases and controls). Eosinophilia and high IgE levels are typical responses to helminth infection, specially in patients with larval migration through tissues (Allen \& Maizels 1996).

Although we do not have a definite explanation for this association, we hypothesize that nematode infection enhances staphylococcal infection in children. Considering the data in the literature, we assert that the immunomodulation induced by nematode infection, as manifested by a Th 2 shift in the immune response, is the main factor facilitating bacterial infection.

Th2 shift in immune response is a hallmark of helminth infection (DelPrete et al. 1991, Bentwich et al. 1996,1999, Allen \& Maizels 1996, Finkelman et al. 1997, Kalinkovich et al. 1998) and down-regulation of Th1 responses is demonstrated in some experimental models (Pearlman et al.1993, Ferreira et al. 1995, Allen \& Mac Donald 1998, Macedo et al. 1998) and in humans (Kalinkovich et al. 1998, Borkow et al. 2000). The possibility of IgE production in response to Staphylococcus, as in Job's syndrome (Hill \& Quie 1974, Scopfer et al. 1980, Donabedian \& Gallin 1982, Berger et al. 1988), cannot be ruled out, because helminth infection can act as an adjuvant for IgE production against unrelated antigens (Turner et al. 1979). It is thus possible that in helminth infections, chemotactic defects in leukocytes are induced by high tissue histamine levels, released

TABLE III

Age, gender, birthplace, stool examination, and serology for Toxocara in patients with staphylococcal infection $(\mathrm{N}=80)$ and controls $(\mathrm{N}=110)$

\begin{tabular}{|c|c|c|c|}
\hline Variables & Staphylococcal & Controls & $\mathrm{p}^{a}$ or $\mathrm{OR}(95 \% \mathrm{CI})$ \\
\hline $\begin{array}{l}\text { Age } \\
\text { mean } \pm \text { sd } \\
\text { median } \\
\text { range }\end{array}$ & $\begin{array}{c}5.75 \pm 3.75 \\
5.00 \\
1-14\end{array}$ & $\begin{array}{l}5.94 \pm 4.48 \\
\quad 4.00 \\
1-15\end{array}$ & 0.761 \\
\hline $\begin{array}{l}\text { Gender } \\
\text { male } \\
\text { female }\end{array}$ & $\begin{array}{l}52(65.0 \%) \\
28(35.0 \%)\end{array}$ & $\begin{array}{l}64(58.2 \%) \\
46(41.8 \%)\end{array}$ & 0.211 \\
\hline $\begin{array}{l}\text { Origin } \\
\text { Greater Metropolitan Vitória } \\
\text { other municipalities }\end{array}$ & $\begin{array}{l}59(73.8 \%) \\
21(26.3 \%)\end{array}$ & $\begin{array}{l}72(65.5 \%) \\
38(34.5 \%)\end{array}$ & 0.281 \\
\hline $\begin{array}{l}\text { Stool test } \\
\text { positive } \\
\text { negative }\end{array}$ & $\begin{array}{l}55(68.8 \%) \\
25(31.2 \%)\end{array}$ & $\begin{array}{l}25(22.7 \%) \\
85(77.3 \%)\end{array}$ & $7.48(3.90-14.32)$ \\
\hline $\begin{array}{l}\text { Serology for Toxocara } \\
\text { positive } \\
\text { negative }\end{array}$ & $\begin{array}{l}47(58.8 \%) \\
33(41.2 \%)\end{array}$ & $\begin{array}{l}32(29.1 \%) \\
78(70.9 \%)\end{array}$ & $3.47(1.89-6.36)$ \\
\hline Positive for intestinal nematode or Toxocara & $65(81.2 \%)$ & $46(41.6 \%)$ & $6.02(3.06-11.86)$ \\
\hline
\end{tabular}

$a$ : one-way ANOVA or $\chi^{2}$ test; $b$ : presence of at least one intestinal nematode 
by mast cells or basophils sensitized with IgE specific for nematode or staphylococcal antigens, as it is admitted in Job's syndrome (Hill \& Quie 1974, Berger et al. 1988). A chemotactic defect in neutrophils with improvement after treatment was reported in one child with toxocariasis (Caldwell et al. 1980). Recently it was demonstrated that chronic immune activation associated with intestinal helminths induced impaired signal transduction and anergy in humans (Borkow et al. 2000). Such impaired immune function may exist in children with nematode infections, reducing the capacity of these children to cope with staphylococcal infections.

Another possible explanation for the increased susceptibility to staphylococcal infection in children with nematodes is the trapping of bacteria in granulomas around nematode larvae or antigens. This bacterial trapping would be important for localization of infections, since it occurs in pyogenic liver abscess (Ferreira et al.1996, Pereira et al. 1999, Moreira-Silva \& Pereira 2000). As shown in Table I, most staphylococcal infections diagnosed in 80 children had a defined site: pyomyositis, pyoarthritis, osteomyelitis, or pyogenic liver abscess. It is thus possible that granulomas around larvae or antigens occurring in different tissues during Toxocara infection may be areas of bacterial trapping, enhancing the infection. In fact, the spectrum of staphylococcal infection observed here in children with nematode infection is different from that reported in allergic patients in whom the staphylococcal infection is observed in the target organ for allergy, frequently skin and lungs (David et al. 1986). Trapping of bacteria in granulomas and the immunomodulation induced by parasite antigens, acting together, may enhance staphylococcal infection in children with nematode infection, producing higher frequencies of deep abscesses than in atopic patients.

Malnutrition was present in children with staphylococcal infection (indicated by hemoglobin levels, Table III), but nutritional status was not different from control patients. While malnutrition may be a predisposing factor for staphylococcal infection in the tropics (Hendricks et al. 1997), the hemoglobin levels were similar, indicating a moderate malnutrition in both groups. It may thus be argued that malnutrition was not a relevant contributing factor for the differences in frequency of staphylococcal infection in these groups.

Another possibility that cannot be discarded is the presence of a common genetic defect that predisposes to both nematode and staphylococcal infections. A genetic factor could also predispose patients to nematode infections and allergies, with the two acting together to facilitate staphylococcal infection. Genetic factors enhancing helminthic infections have not been demonstrated in humans (Chan et al. 1994a, b) and the relationship between helminthic infection and allergy is poorly understood: there are conflicting results showing that helminthic infection can increase (Joubert et al. 1980, Bujis et al. 1994, Lynch \& DiPrisco 1994) or decrease (Godfrey 1975, Moqbel \& Pritchard 1990, Hagel et al, 1993, Lynch et al. 1998) the allergic reactions, depending on the parasite load (Lynch et al. 1998). In this study, we did not investigate the aller- gic status of the children, neither was a quantitative study of parasite load performed.

Further prospective studies are necessary to confirm the association reported here. Also further investigation on chemotactic and microbicidal activity of phagocytes, on production of anti-staphylococcus IgE and on the status of Th1 responses in children with intestinal nematodes or Toxocara infection are necessary to verify the hypothesis described above.

\section{REFERENCES}

Allen JE, MacDonald AS 1998. Profound immunosuppression of cellular proliferation mediated by the secretions of nematodes. Parasite Immunol 20: 241-247.

Allen JE, Maizels RM 1996. Immunology of human helminth infection. Int Arch Allergy Immunol 109: 3-10.

Ash LR, Oriel TC 1987. Parasites: a Guide to Laboratory Procedures and Identification, ASCP Press, Chicago, 244 pp.

Bentwich Z, Kalinkovich A, Weisman Z, Borkov G, Beyers N, Beyers N 1999. Can eradication of helminthic infections change the face of AIDS and tuberculosis? Immunol Today 20: 485-487.

Bentwich Z, Weisman Z, Moroz C, Bar-Yehuda S, Kalinkovich A 1996. Immune disregulation in Ethiopian immigrants in Israel: relevance to helminth infections? Clin Exp Immunol 103: 239-243.

Berger M, Kirkpatrick H, Goldsmith BK 1988. IgE antibodies to Staphylococcus aureus and Candida albicans in patients with the syndrome of hyperimmunoglobulinemia E and recurrent infections. J Immunol 125: 2437-2443.

Borkow G, Leng Q, Weisman Z, Stein M, Galai N, Kalinkovich A, Bentwich Z 2000. Chronic immune activation associated with intestinal helminth infections results in impaired signal transduction and anergy. J Clin Invest 106: 10531060.

Bujis JG, Borsboom G, van Gemund JJ, Hazebroeck A, van Dongen PA, van Knapen F, Neijens H 1994. Toxocara seroprevalence in 5-year-old elementary schoolchildren: relation with allergic asthma. Am J Epidemiol 140: 839-847.

Caldwell K, Lobell M, Coccia PF 1980. Mitogenic response to Toxocara antigen and chemotactic defect in visceral larva migrans. Am J Dis Child 134: 845-847.

Chan L, Bundy DAP, Kan SP 1994a. Aggregation and predisposition to Ascaris lumbricoides and Trichuris trichiura at the familial level. Trans R Soc Trop Med Hyg 88: 46-48.

Chan L, Bundy DAP, Kan SP 1994b. Genetic relatedness as a determinant predisposition to Ascaris lumbricoides and Trichuris trichiura infections. Parasitology 108: 77-78.

David TJ, Cambridge GC 1986. Bacterial infection and atopic eczema. Arch Dis Child 61: 20-23.

De Savigny DH, Voller A, Woodruff AW 1979. Toxocariasis: serological diagnosis by enzyme immunoassay. J Clin Pathol 32: 284-288.

DelPrete GF, DeCarli M, Mastromauro C, Biagiotti R, Macchia D, Falagiani P, Ricci M, Romagnani S 1991. Purified protein derivate of Mycobacterium tuberculosis and excretory-secretory antigens of Toxocara canis expand in vitro human $\mathrm{T}$ cells with stable and opposite (type $1 \mathrm{~T}$ helper or type $2 \mathrm{~T}$ helper) profile of cytokine production. J Clin Invest 88: 346350 .

Donabedian H, Gallin JI 1982. Mononuclear cells from patients with the hyperimmunoglobulinemia E recurrent infections syndrome produce an inhibitor of leukocyte chemotaxis. J Clin Invest 69: 1155-1158.

Feigin RD, Cherry JD 1992. Textbook of Pediatric Infectious Diseases (3rd ed.), WB Saunders Co, Philadelphia, 2395 pp. 
Ferreira AP, Faquim ES, Abrahmsohn IA, Macedo MS 1995. Immunization with Ascaris suum extract impairs T cell function in mice. Cell Immunol 162: 202-210.

Ferreira MAB, Pereira FEL, Musso C, Dettogni RV 1996. Pyogenic liver abscess in children: observations in Espirito Santo State, Brazil. Arq Gastroenterol (São Paulo) 34: 49-54.

Finkelman FD, Shea-Donahue T, Goldhill J, Sullivan CA, Morris SC, Madden KB, Gause WC, Urban Jr JF 1997. Cytokine regulation of host defense against parasitic gastrointestinal nematodes. Lessons from studies with rodent models. Annu Rev Immunol 15: 505-533.

Gambhir IS, Singh DS, Gupta SS, Gupta PR, Kumar M 1992. Tropical pyomyositis in India: a clinico-histopathological study. J Trop Med Hyg 95: 42-46.

Godfery RC 1975. Asthma and IgE levels in rural and urban communities of the Gambia. Clin Allergy 5: 201-207.

Hagel I, Lynch NR, DiPrisco MC, López R, Garcia R 1993. Allergic reactivity of children of different socioeconomic levels in tropical population. Int Arch Allergy Immunol 101: 209-214.

Hendricks MK, Moore SW, Millar AJW 1997. Epidemiological aspects of liver abscesses in children in Western Cape Province of South Africa. J Trop Pediatr 43: 103-105.

Hill HR, Quie PG 1974. Raised serum IgE levels and defective neutrophil chemotaxis in three children with eczema and recurrent bacterial infections. Lancet 1: 183-187.

Joubert JR, Van-Schalkwyk DJ, Turner KJ 1980. Ascaris lumbricoides and the human immunogenic response: enhanced IgE-mediated reactivity to common inhaled allergens. S Af Med J 57: 409-412.

Kalinkovich A, Weisman Z, Greenberg Z, Nahmias J, Eitan S, Stein M, Bentwich Z 1998. Decreased CD4 and increased CD8 counts with Tcell activation is associated with chronic helminth infection. Clin Exp Immunol 114: 414-421.

Lambertucci JR, Teixeira R, Navarro MMM, Coelho PMZ, Ferreira MD 1990. Liver abscess and schistosomiasis. A new association. Rev Soc Brasil Med Trop 23: 239-240.

Lynch NR, DiPrisco MC 1994. High allergic reactivity in a tropical environment. Clin Allergy 14: 233-240.

Lynch NR, Hagel I, Palenque ME, DiPrisco MC, Escudero JE, Corao LA, Sandia JA, Ferreira LJ, Botto C, Perez M, Souef PN 1998. Relationship between helminth infection and IgE response in atopic and non-atopic children in a tropical environment. J Allergy Clin Immunol 101: 217-221.

Lynch NR, Hagel I, Vargas I, Rotundo A, Varela MC, Di Prisco MC, Hodgen NA 1993. Comparable seropositivity for ascariasis and toxocariasis in tropical slum children. Parasitol Res 79: 547-550.

Macedo MS, Faquim M, Ferreira AP, Abrahmsohn IA 1998. Immunomodulation induced by Ascaris suum extract in mice: effect of anti-interleukin-4 and anti-interleukin-10 antibodies. Scand J Immunol 47: 10-18.

Moqbel R, Pritchard DI 1990. Parasites and allergy; evidence for a cause and effect relationship. Clin Exp Allergy 20: 611-618.

Moreira-Silva SF, Pereira FEL 2000. Intestinal nematodes, Toxocara infection and pyogenic liver abscess in children: a possible association. J Trop Pediatr 46: 167-172.

Pearlman E, Kazura JW, Hazlett Jr FE, Boom H 1993. Modulation of murine cytokine responses to mycobacterial antigens by helminth-induced T helper 2 cell responses. $J$ Immunol 151: 4857-4864.

Pereira FEL, Musso C, Castelo JS 1999. Pathology of pyogenic liver abscess in children. Pediatr Developm Pathol 2: 537-543.

Rayes AA, Nobre V, Teixeira DM, Serufo JC, Brasileiro-Filho G, Antunes CM, Lambertucci JR 2000. Tropical pyomyositis and human toxocariaisis: a clinical and experimental study. Am J Med 100: 422-425.

Rayes AA, Teixeira DM, Cerufo JC, Nobre V, Antunes CM, Lambertucci JR 2001. Human toxocariaisis and pyogenic liver abscess: a possible association. Am J Gastroenterol 96: 563-566.

Scopfer K, Douglas SD, Wilkinson BJ 1980. Immunoglobulin E antibody against Staphylococcus aureus cell wall in the sera of patients with hyperimmunoglobulinemia $\mathrm{E}$ and recurrent infections. Infect Immun 27: 563-568.

Teixeira R, Ferreira MD, Coelho PMZ, Brasileiro-Filho G, Azevedo-Junior GM, Lambertucci JR 1996. Pyogenic liver abscess and acute schistosomiasis mansoni: report of 3 cases and experimental study. Trans $R$ Soc Trop Med Hyg 90: 280-283.

Turner LK, Feddema L, Quinn EH 1979. Non-specific potentiation of immunoglobulin $\mathrm{E}$ by parasitic infection in man. Int Arch Allerg Appl Immunol 58: 2323-236. 